\title{
Simulators Usage Assessment for Higher Military Readiness
}

\author{
Svajone BEKESIENE ${ }^{1}$, Gediminas PRŪSEVIČIUS ${ }^{2}$
}

1,2 General Jonas Žemaitis Miltitary Academy of Lithuania, Silo str. 5A, LT-10322 Vilnius

E-mails: ${ }^{1}$ svajone.bekesienel@lka.lt

\begin{abstract}
In the 21 st century technology has reached a sufficiently advanced level. The armed forces of NATO countries are actively implementing simulation systems into the military training process. Simulators save resources and allow troops to train in situations that would be very dangerous or impossible to create in the real world. Properly trained soldiers are a key part of strong and challenging army. Therefore, Lithuanian military training is constantly being improved and new methods are being sought to ensure the highest quality process to develop soldiers' competence. In order to properly evaluate the effectiveness of the simulators used in the Lithuanian Armed Forces training unit, it is necessary to determine if simulators help to prepare soldiers capable of analysing situations properly and to be modern in combat. Also identify fields for improvement in the use of existing simulators related to military training, provide rational solutions to eliminate identified problems for military training. The aim of this study was to identify Lithuanian Armed Forces combat training centre improvement fields for the simulators' use in the individual and collective training.
\end{abstract}

KEY WORDS: NATO standards, individual and collective military training, JCATS simulators, MILES (I-HITS) simulators, efficiency

\section{Introduction}

Highest Military readiness training is one of the main tasks of each country's military. The purpose of this training is to train modern troops capable for properly analyzing situations and to ensure national security. Nowadays the technology has reached a sufficiently advanced level and the armed forces of NATO countries are actively implementing simulation systems into the military training process. Simulators help to save resources and allow troops to train in situations that would be very dangerous or impossible to create in the real world. Properly trained soldiers are the key part of strong and challenging army. NATO uses simulators to achieve training goals. According to COMTEX (2018), 993 billion \$ was spent on the purchase of simulators. It is predictable that global market demand in 2023 year will be $6.92 \%$ higher than in 2018 year. This means that the simulators will continue to expand throughout NATO's military infrastructure, especially in the military training process.
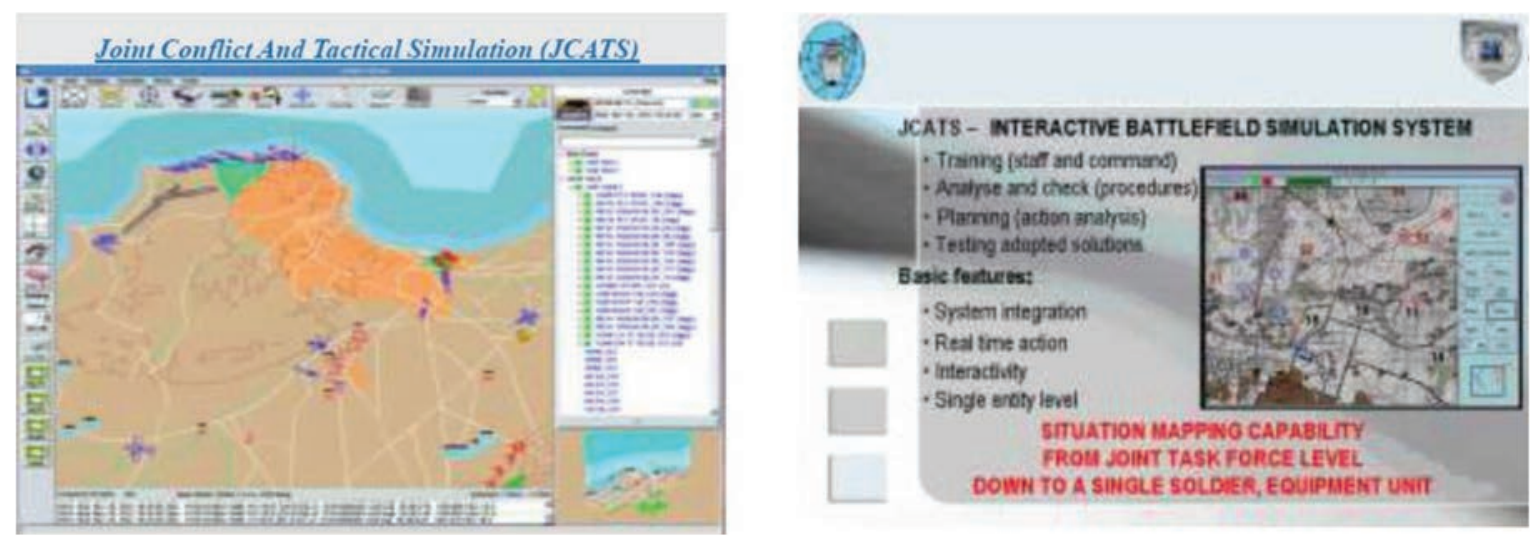

Fig. 1. JCATS functionalities [19].

Additionally, can be said that NATO countries are more advanced than other countries in the world in integrating simulators into individual and collective military training. Of course, when comparing NATO nations, it

\footnotetext{
${ }^{1}$ Corresponding author.

E-mail address: svajone.bekesiene@1ka.lt
} 
must be acknowledged that the United States and Canada dominate in the use of simulators for troop training [1-4, 7, 12-15].

The combat training of Lithuanian soldiers is constantly being improved and new methods which would ensure the highest quality process of the development of soldier's competencies are being searched for. According to the National Defense System Strategic Action Plan for 2019 - 2021, the Lithuanian Armed Forces School of Stasys Rashtix and ARCTC (General Adolfas Ramanauskas Combat Training Center) plan to train up to 2541 civil servants in specialty and refresher training courses every year. Therefore, the solutions for the use of simulators in the training of soldiers will not only be constantly updated, but will be enhanced by expanding the use of simulators in the military training process according to the requirements placed by the Lithuanian Armed Forces.

The aim of this plan is to use the simulators such as JCATS (Fig.1) for developing soldiers' competencies, and according to NATO standards to train modern troops that will be able to operate in a complex operational environment. The simulator is one of the most modern and important military training tools. So, the inefficient use of simulators is one of the biggest problems in soldiers' preparation for real combat tasks. The training of LK soldiers is regularly improved in accordance with NATO standards, but the Lithuanian Armed Forces face troop training problems due to inefficient use of simulators.

The research main goals were few. The first, properly evaluate the effectiveness of the simulators used for the Lithuanian Armed Forces training, and the second, to determine the simulators value for soldiers' preparation to be possible analysing situations properly and to be modern in combat. The object of this research analysis was chosen the simulators used for soldiers' individual and collective training at the Lithuanian Armed Forces Combat Training Centre.

\section{Research Design}

There was used the primary data collection and analysis. To achieve study goal, was chosen survey method - survey questionnaires. The questionnaire prepared for the study consisted of categorical questions measured on the Likert scale. The answers to the questions were evaluated according to the strength / significance of the criterion for the respondent - from 1(not significant) to 7 (high significant) points system. Notable, that the components of the quantitative analysis are the factors that determine the satisfaction and dissatisfaction of the simulators' usage in the military preparation process.

The rationale behind the method is an attempt to reduce the complexity of the data by decreasing the number of variables that need to be considered. The PCA helped to identify the latent (invisible) factors affecting the soldiers' individual and collective training with simulators quality. Completed PCA allowed to obtain several generalized variables from several variables similar in their sense, thus the most important causal criteria were signed out. According to the methodology, the PCA was performed in several stages: 1) it was checked whether the data were suitable for the factor analysis; 2) separation of factors; 3) rotation and interpretation of factors; 4) calculation of estimates of factor values [11].

Table 1.

Criteria for the simulator utilization efficiency evaluation

\begin{tabular}{|c|l|l|}
\hline Code & \multicolumn{1}{|c|}{ Criteria } & \multicolumn{1}{|c|}{ Description } \\
\hline A & Simulators' hardware / software & $\begin{array}{l}\text { To have reliable simulators to ensure efficient unit performance } \\
\text { during exercises, it is important to upgrade the simulator } \\
\text { software and hardware regularly (Rodrigo, 2019). }\end{array}$ \\
\hline B & $\begin{array}{l}\text { Possibilities of simulator training } \\
\text { scenarios. }\end{array}$ & $\begin{array}{l}\text { Simulator training scenarios give troops the opportunity to } \\
\text { learn tactics in an environment that real polygons cannot offer } \\
\text { (Michelle, 2014). }\end{array}$ \\
\hline C & $\begin{array}{l}\text { Proper preparation of exercises } \\
\text { with the simulator. }\end{array}$ & $\begin{array}{l}\text { In order to use the simulators effectively, the staff must be } \\
\text { properly trained, environment and simulator must be properly } \\
\text { prepared (David E. Johnson, Jennifer D. P. Moroney, Roger Cliff } \\
\text { M. Wade Markel, 2009). }\end{array}$ \\
\hline D & $\begin{array}{l}\text { Evaluation report generated by the } \\
\text { simulator. }\end{array}$ & $\begin{array}{l}\text { The simulator provides an objective and qualitative assessment } \\
\text { of the soldier's progress during exercise. This encourages the } \\
\text { rapid progress of the troops and the collective (Sameer, 2013). }\end{array}$ \\
\hline
\end{tabular}

Source: authors' 
Additional component of the empirical study was an expert survey in which a specific category of respondents was interviewed: instructors with long-term experience in training soldiers when using simulators. Notable, the experts can be named the most highly qualified specialists in the respective field. The instructors selected for this study met the essential requirements [11]. The selection of the expert evaluation method was a logical way for analysis of the problem. Therefore, when quantifying and formally processing data, this method was the most appropriate to assess the simulator utilization efficiency that determine warriors' motivation and willingness to learn to perform military tasks with the help of simulators.

The experts' survey method was chosen because of its logical analysis of the problem, and was the most appropriate to evaluate the factors influencing simulators usage effectiveness. This method was also chosen due to the efficiency of the results obtained and the short duration of the study. Four main directions, which are described in Table 1, were chosen after scientific literature analysis for experts' survey. The statistical software package SPSS version 26 was used for the collected experts' data analysis and for the PCA analysis as well [1-4, 15, 18, 17].

\subsection{Description of the Principal Component Analysis Method}

Principal components analysis is basically a technique of data reduction that aims to produce a small number of resulting variables that can be used in place of the larger number of original variables to simplify subsequent analysis of the data. The principal component variables y1, y2, .., yq are defined to be linear combinations of the original variables $\mathrm{x} 1, \mathrm{x} 2, \ldots, \mathrm{xq}$ that are uncorrelated and account for maximal proportions of the variation in the original data, i.e., $\mathrm{y} 1$ accounts for the maximum amount of the variance among all possible linear combinations of $\mathrm{x} 1$, ..., xq, y2 accounts for the maximum variance subject to being uncorrelated with y1 and so on.

Explicitly, the principal component variables are obtained from $\mathrm{x} 1, \ldots, \mathrm{xq}$ as follows:

$$
\begin{aligned}
& y_{1}=a_{11} x_{1}+a_{12} x_{2}+\cdots+a_{1 q} x_{q} \\
& y_{2}=a_{21} x_{1}+a_{22} x_{2}+\cdots+a_{2 q} x_{q} \\
& \vdots \\
& y_{q}=a_{q 1} x_{1}+a_{q 2} x_{2}+\cdots+a_{q q} x_{q}
\end{aligned}
$$

where the coefficients $(i=1, \ldots, q, j=1, \ldots, q)$ are chosen so that the required maximal variance and uncorrelated conditions hold. Since the variances of the principal components' variables could be increased without limit, simply by increasing the coefficients that define them, a restriction must be placed on these coefficients.

The constraint usually applied is that the sum of squares of the coefficients is one so that the total variance of all the components is equal to the total variance of all the observed variables. It is often convenient to rescale the coefficients so that their sum of squares is equal to the variance of that component they define. In the case of components derived from the correlation matrix of the data, these rescaled coefficients give the correlations between the components and the original variables. It is these values that are often presented as the result of a principal components analysis.

The coefficients defining the principal components are given by what are known as the eigenvectors of the sample covariance matrix, S, or the correlation matrix, R. Components derived from $\mathbf{S}$ may differ considerably from those derived from $\mathbf{R}$, and there is not necessarily any simple relationship between them. In most practical applications of principal components, the analysis is based on the correlation matrix, e.g., on the standardized variables, since the original variables are likely to be on very different scales so that linear combinations of them will make little sense.

Principal component scores for an individual with vector of variable values can be obtained by simply applying the derived coefficients to the observed variables, generally after subtracting the mean of the variable, i.e., from the equations

$$
\begin{aligned}
& y_{i 1}=a_{1}^{T}\left(\boldsymbol{X}_{i}+\overline{\boldsymbol{X}}\right) \\
& \vdots \\
& y_{i q}=a_{q}^{T}\left(\boldsymbol{X}_{i}+\overline{\boldsymbol{X}}\right)
\end{aligned}
$$

where, and is the mean vector of the observations.

Generally, the PCA is a multivariate technique for transforming a set of related (correlated) variables into a set of unrelated (uncorrelated) variables that account for decreasing proportions of the variation of the original observations.

Study results are presented in the 3.2. section below. 


\section{Results and Discussions}

The results of these investigations showed that the simulators used or purchased by the Lithuanian Armed Forces meet the NATO requirements, but the combat training needs and expectations of the soldiers serving in the Lithuanian Armed Forces are unsatisfactory. Detailed survey results are presented in the sections 3.1, 3.2 and 3.3.

\subsection{Descriptive Analysis Outcomes}

The questionnaire was sent to the general e-mail of the LAF military units. The questionnaires were given the opportunity to fill in the soldiers who have the competence to evaluate the efficiency of the of simulators used by LAF for soldiers training. The special units mostly use simulators of the Lithuanian Armed Forces was chosen for this study.

Respondents were asked to evaluate eight statements on a seven-point Likert-type scale. The majority of respondents were 31-40 years old; nearly half of the respondents (48\%) had 10-15 years of work experience and only $2 \%$ of participants had less than 5 years.

Firstly, the survey participants were asked whether they were familiar with JCATS or MILES training systems. Secondly, participants had to indicate their level of familiarity with mentioned simulators. The familiarity layers were divided as follows: participant have heard about JCATS or MILES; was in the observed training, participated in training). Subsequently, participants who were acquainted with the training system were presented with a series of items about system reliability, access to or quantity of training, and other factors that simplify or inhibit use of the simulators. The survey also included general items about use of other methods for collective training, general questions about perceived requirements for reliability in training by simulations, how respondents learned to plan virtual collective training events, gaming experience, demographic characteristics and job experience, and views on how to improve the effectiveness of virtual collective training. The survey took 15 to 20 minutes to complete. General interpretations about simulator training were associated with individual characteristics of respondents. In the Table 2 is presented the descriptive data analysis of simulators assessment by eight statements:

T1 - JCATS/ MILES (I-HITS) is an effective tool for training start-up staff to perform collective tasks;

T2 - JCATS /MILES (I-HITS) is an effective tool for training experienced staff to perform collective tasks;

T3 - JCATS/ MILES (I-HITS) is effective to apply with other learning systems;

T4 - JCATS/ MILES (I-HITS) provides a clear assessment of unit performance;

T5 - JCATS/ MILES (I-HITS) develops the competence of soldiers to perform collective tasks;

T6 - JCATS/ MILES (I-HITS) is an effective tool for preparing staff for real tasks;

T7 - The need for JCATS/ MILES (I-HITS) is growing;

T8 - With the JCATS/ MILES (I-HITS) simulator, training opportunities for soldiers are expanding.

Table 2.

Descriptive data analysis for the simulator utilization efficiency evaluation

\begin{tabular}{|c|c|c|c|c|c|c|}
\hline \multirow{2}{*}{ Statement code } & \multicolumn{5}{|c|}{ SIMULATOR } \\
\cline { 2 - 7 } & \multicolumn{3}{|c|}{ MILES (I-HITS) } & MCATS \\
\cline { 2 - 7 } & Mean & Median & Std. Deviation & Mean & Median & Std. Deviation \\
\hline T1 & 3 & 3 & 0.894 & 2.73 & 3 & 0.905 \\
\hline T2 & 2.56 & 2.5 & 0.964 & 3 & 3 & 0.775 \\
\hline T3 & 3.29 & 3 & 0.726 & 2.11 & 2 & 0.782 \\
\hline T4 & 3.56 & 4 & 0.629 & 2.8 & 3 & 0.632 \\
\hline T5 & 3.38 & 3 & 0.500 & 3.17 & 3 & 0.577 \\
\hline T6 & 3.71 & 4 & 0.470 & 3.2 & 3 & 0.632 \\
\hline T7 & 3.53 & 4 & 0.516 & 3.27 & 3 & 0.467 \\
\hline T8 & 3.47 & 4 & 0.624 & 3.3 & 3 & 0.483 \\
\hline
\end{tabular}

Source: authors 'calculations 


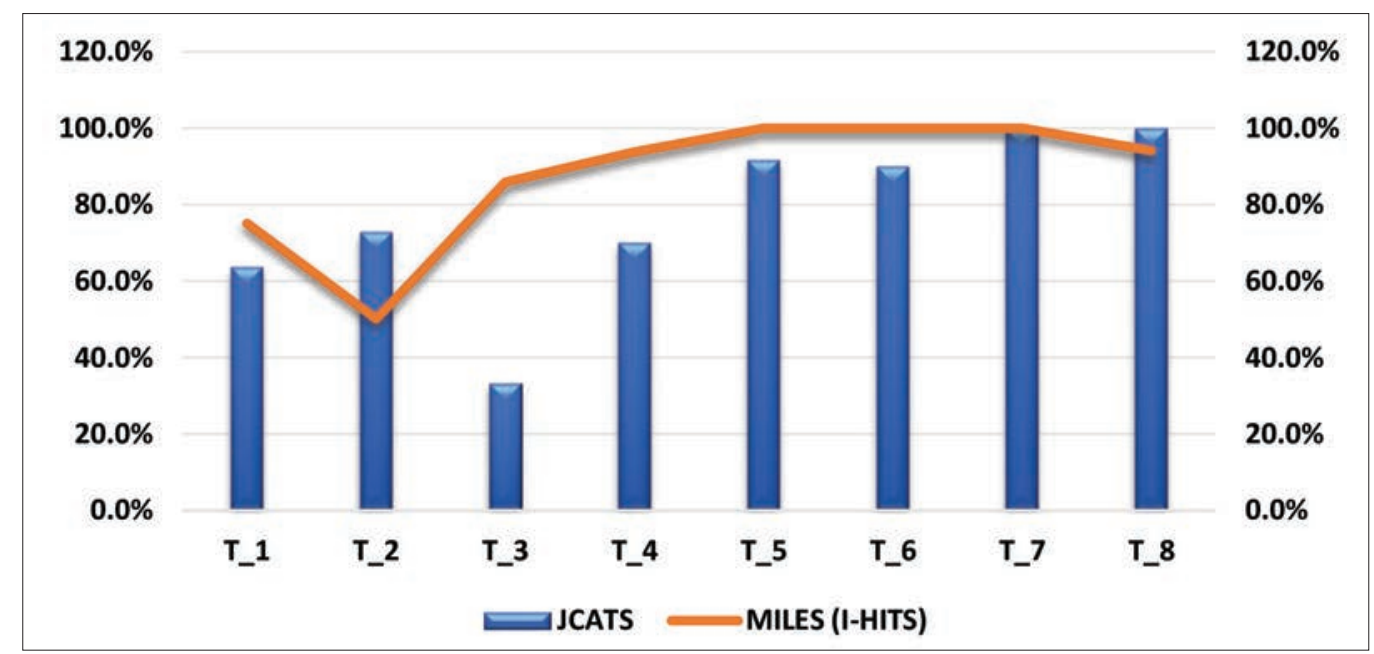

Fig. 2. Evaluation of JCATS and MILES (I-HITS) simulators utilization efficiency with respect to respondents' ratings. Source: authors 'calculations

Based on the analysis of statistical data, it can be stated that the efficiency of using MILES (I-HITS) simulator in preparing soldiers for real tasks is the highest, because the average of T6 statement is 0.371 (maximum). However, the efficiency of using the MILES (I-HITS) simulator is the lowest in preparing experienced personnel to perform military tasks, as the average of the T2 statement is only 2.56 (the lowest). When evaluating the JCATS simulator, its maximum utilization efficiency is reflected in the choice of soldier training options in the choice, as the T8 average is 3.3 (maximum). The lowest efficiency of using the JCATS simulator occurs when the JCATS simulator is tried to be used with other training systems to prepare soldiers for collective tasks. This is shown by the average of the T3 statement - 2.11 (lowest).

The summary of quantitative research results according eight measurements for JCATS and MILES (I-HITS) simulators utilization are presented in percent in the Fig. 2. Based on the collected data analysis it can be stated that the efficiency of the MILES (I-HITS) simulator use in the military training process is estimated at $83 \%$. The JCATS simulator utilization efficiency is estimated at $73 \%$.

\subsection{Principal Component Analysis Results}

The opinion survey method was used to take out the information about how the simulators fulfill the respondents' willingness to expand their military abilities [16-18]. The operators, instructors, training specialists, and training participants were interviewed. Their opinions regarding the training effectiveness of a training by JCATS or MILES simulators were gathered.

A questionnaire was developed and pilot testing was performed, aiming to ensure the adequacy of the survey instrument. The answers were given on a seven-point scale ranging from (1) not significant to (7) high significant. All questions were posed to determine which aspects of the JCATS or MILES simulator do or do not contribute to a high transfer of training. Accordingly, collected data were analyzed to examine changes in user attitudes, system usage rates, and training performance from the beginning to the end.

The Principal components analysis method and SPSS 26v software was used for opinion surveys. The purpose of this analysis was to identify the main latent (invisible) factors that influence the successful utilization of simulators. The Bartlett's test of sphericity (BTS) tests the hypothesis that variables correlation matrix is an identity matrix, which would indicate that chosen variables are unrelated and therefore unsuitable for structure detection. Small values (less than 0.05) of the significance level indicate that a factor analysis may be useful with collected data. Bartlett's test of sphericity confirmed that the collected block of variables reveals the essence of the researched problem in a statistically significant way (sig. $=0,001)$. The Kaiser - Meyer - Olkin (KMO) measure of sampling adequacy is a statistic that indicates the proportion of variance in collected variables that might be caused by underlying factors. In generally, the high KMO values (close to 1.0) indicate that an analysis may be useful with collected data.

According to the calculations both tests, the KMO and Bartlett's test of sphericity, demonstrated the adequacy of the collected data for chosen statistical analysis: for JCATS study questionnaire the KMO $=0.778$ (BTS, sig. $=$ $0,001)$ and for MILES study questionnaire the KMO =0.663 (BTS, sig. $=0,001)$. Moreover, study results indicated that the 87.8 percent's variance variables can be explained by four distinguished factors (for JCATS simulator) and 66.3 percent's the variances in the variables can also be explained by 4 factors (for MILES simulator). The indicated factors related to the utilization of simulators in the LAF training unit are described in Table 5 and Table 6. 
Table 5.

Recognized main latent factors for JCATS simulator utilization assessment

\begin{tabular}{|c|c|c|c|}
\hline No. & Latent factors & Statements for JCATS simulator utilization assessment & $\begin{array}{l}\text { Correlation } \\
\text { coefficients }\end{array}$ \\
\hline 1 & $\begin{array}{l}\text { Training effectiveness for } \\
\text { experienced staff }\end{array}$ & $\begin{array}{l}\text { JCATS develops the competence of soldiers in performing } \\
\text { collective tasks; } \\
\text { JCATS is a valuable tool in preparing staff for real tasks; } \\
\text { JCATS is an effective tool for training experienced staff to } \\
\text { perform collective tasks. }\end{array}$ & $\begin{array}{l}0.901 \\
0,904 \\
0,878\end{array}$ \\
\hline 2 & $\begin{array}{l}\text { High technical } \\
\text { capabilities }\end{array}$ & $\begin{array}{l}\text { JCATS provides a variety of scenarios; } \\
\text { JCATS effectively replicates the parameters of military } \\
\text { equipment; } \\
\text { JCATS conveys realistic combat stress situations; } \\
\text { JCATS perfectly replicates various weapon detection } \\
\text { systems. }\end{array}$ & $\begin{array}{l}0,814 \\
0,752 \\
0,753 \\
0,718\end{array}$ \\
\hline 3 & Time-saving capability & $\begin{array}{l}\text { JCATS allows military units to perform many collective } \\
\text { tasks in a very short time; } \\
\text { JCATS facilitates planning and preparation for collective } \\
\text { assignments. }\end{array}$ & $\begin{array}{l}0,769 \\
0,760\end{array}$ \\
\hline 4 & Shortcomings & $\begin{array}{l}\text { JCATS requires significant human resources; } \\
\text { JCATS is not an effective tool for training start-up staff to } \\
\text { perform collective tasks. }\end{array}$ & $\begin{array}{l}0,942 \\
0,892\end{array}$ \\
\hline
\end{tabular}

Source: authors'

Table 6.

Recognized main latent factors for JCATS simulator utilization assessment

\begin{tabular}{|c|l|l|c|}
\hline No. & \multicolumn{1}{|c|}{ Latent factors } & \multicolumn{1}{|c|}{$\begin{array}{c}\text { Statements for MILES (I-HITS) simulator utilization } \\
\text { assessment }\end{array}$} & $\begin{array}{c}\text { Correlation } \\
\text { coefficients }\end{array}$ \\
\hline 1 & $\begin{array}{l}\text { Realistic combat stressful } \\
\text { situations }\end{array}$ & $\begin{array}{l}\text { MILES (I-HITS) simulator conveys realistic combat } \\
\text { stress situations; } \\
\text { The MILES (I-HITS) simulator effectively replicates } \\
\text { the efficiency of weapon systems; } \\
\text { MILES (I-HITS) simulator provides clear feedback on } \\
\text { the performance of an individual soldier and unit. }\end{array}$ & 0,887 \\
\hline 2 & Collective training benefit & $\begin{array}{l}\text { MILES (I-HITS) allows military units to perform many } \\
\text { collective tasks; } \\
\text { MILES (I-HITS) facilitates planning and preparation } \\
\text { for collective assignments. }\end{array}$ & 0,770 \\
\hline 3 & Time-saving capability & $\begin{array}{l}\text { MILES (I-HITS) simulator enables military units to } \\
\text { perform many tasks in a very short time. } \\
\text { MILES (I-HITS) simulator exercise planning is easy } \\
\text { and fast. }\end{array}$ & 0,924 \\
\hline 4 & Growing demand & $\begin{array}{l}\text { The need for simulators is increasing; } \\
\text { The use of simulators expands the possibilities of train- } \\
\text { ing soldiers. }\end{array}$ & 0,782 \\
\hline
\end{tabular}

Source: authors'

Principal component data analysis leads to a statistically significant conclusion that the simulators for collective tasks performing utilization assessment can be acknowledged by extracted latent factors:

I. JCATS simulator by four latent factors (Table 5):

- Training effectiveness for experienced staff; 
- High technical capabilities,

- Time-saving capability;

- Shortcomings.

II. MILES (I-HITS) by four latent factors (Table 6):

- Realistic combat stressful situations;

- Collective training benefit,

- Time-saving capability;

- Growing demand.

The study result was additionally discussed with instructors and training specialists who agree that the LAF training unit simulators have areas for improvement. When evaluating the JCATS simulator, the need to improve the exercise preparation process with JCATS simulators was marked, e. g. to develop databases and faster prepare operators; When evaluating the MILES (I-HITS) system there were mentioned two improvements:

- in particular, old MILES equipment needs to be replaced with the new one;

- Exercise preparation with MILES (I-HITS) simulators also need to be improved.

Summarizing the areas for improvement of LAF simulators, instructors pointed out that the main problem is the small number of exercises performed. The above-mentioned training improvements suggested by instructors' according to the JCATS and MILES (I-HITS) simulators would make the training of troops using these simulators much more efficient. Furthermore, the Lithuanian troops training will be more in line with NATO standards, namely high-quality exercise delivery, security, flexibility and a high rating system.

The experts' opinion survey method was chosen as an additional study because of its logical analysis of the problem. The study results are presented and discussed in 3.3 and 3.4. sections below.

\subsection{Study Results by the Expert Opinion}

One of the most important characteristics of empirical research is proper sampling. In the sociological sciences, the representativeness of the sample is closely related to the size of the sample. However, in the expert survey, the size of the sample does not affect the reliability of the results. The expert assessment is based on the assumption that a decision can only be obtained after assessing the consistency of the experts' opinions. After reviewing the results of the expert evaluation of the simulators utilization impact to soldiers' training quality, it is significant to evaluate at the second stage of the study the consistency of experts' opinions by the calculation of Kendall concordance coefficient W [10].

The main focus of this research instrument preparation was the identification of materiality criteria and the composition of the questions to be asked. This study was done in the context of the training program and skills and competencies to be trained. There was applied the quality evaluating of the synthetic training, according the simulator fidelity method, which can evaluate various aspects of the training environment (or the whole training program) in which the device is utilized. This method can be conducted with the operational personnel (named as experts), which have to compare the simulator on its physical, functional, and psychological aspects. This method is based on the assumption that when physical, functional, and psychological fidelity is high, transfer will also be high, and when fidelity is low, transfer will be low [9].

Table 3.

Statements for the simulator's utilization efficiency evaluation

\begin{tabular}{|c|c|c|}
\hline \multirow{7}{*}{$\underset{\bigcup}{\mathscr{U}}$} & CODE & STATEMENT \\
\hline & $\mathrm{C} 1$ & JCATS enables military units to perform many tasks in a very short time. \\
\hline & $\mathrm{C} 2$ & JCATS conveys realistic terrain conditions. \\
\hline & C3 & JCATS exercise planning is easy and fast. \\
\hline & $\mathrm{C} 4$ & JCATS effectively replicates the effectiveness of weapons systems \\
\hline & $\mathrm{C} 5$ & JCATS provides clear feedback on the performance of an individual soldier and unit \\
\hline & C6 & JCATS conveys realistic combat stress situations \\
\hline \multirow{6}{*}{ 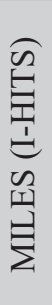 } & C1 & The MILES (I-HITS) simulator enables military units to perform many tasks in a very short time. \\
\hline & $\mathrm{C} 2$ & The MILES (I-HITS) simulator conveys realistic terrain conditions. \\
\hline & C3 & MILES (I-HITS) simulator exercise planning is easy and fast. \\
\hline & $\mathrm{C} 4$ & The MILES (I-HITS) simulator effectively replicates the efficiency of weapon systems. \\
\hline & C5 & MILES (I-HITS) simulator provides clear feedback on the performance of an individual soldier and unit. \\
\hline & C6 & The MILES (I-HITS) simulator conveys realistic combat stress situations. \\
\hline
\end{tabular}


Table 4.

Statements for the simulator's utilization efficiency evaluation

\begin{tabular}{|c|c|c|c|c|c|c|c|c|c|c|c|c|c|}
\hline \multirow{2}{*}{\multicolumn{2}{|c|}{ SPECIFICATIONS }} & \multicolumn{12}{|c|}{ EVALUATION RESULTS } \\
\hline & & \multicolumn{6}{|c|}{ JCATS } & \multicolumn{6}{|c|}{ MILES (I-HITS) } \\
\hline & & C1 & $\mathrm{C} 2$ & C3 & C4 & C5 & C6 & C1 & C2 & C3 & C4 & C5 & C6 \\
\hline \multirow{6}{*}{ Experts } & E1 & 3 & 6 & 5 & 6 & 7 & 4 & 4 & 6 & 5 & 7 & 6 & 7 \\
\hline & E2 & 4 & 5 & 5 & 6 & 7 & 3 & 5 & 7 & 4 & 6 & 6 & 7 \\
\hline & E3 & 3 & 6 & 4 & 5 & 6 & 4 & 4 & 7 & 4 & 5 & 6 & 7 \\
\hline & E4 & 4 & 6 & 4 & 6 & 6 & 5 & 3 & 6 & 5 & 6 & 5 & 7 \\
\hline & E5 & 4 & 6 & 5 & 6 & 7 & 5 & 3 & 6 & 5 & 7 & 6 & 7 \\
\hline & E6 & 3 & 5 & 4 & 5 & 7 & 4 & 3 & 6 & 4 & 7 & 6 & 7 \\
\hline \multicolumn{2}{|c|}{ Mean } & 3.5 & 6 & 4.5 & 5.7 & 6.7 & 4.2 & 3.7 & 6.3 & 4.5 & 6.3 & 5.8 & 7 \\
\hline \multicolumn{2}{|c|}{ Rank } & 4 & 6 & 5 & 6 & 7 & 4 & 4 & 6 & 5 & 6 & 6 & 7 \\
\hline
\end{tabular}

Source: authors'

According to the methodology, the six experts (training instructors) participated in this study. The experts serving as training instructors' duration average was more than 7 years. They were provided with a prepared questionnaire. Additionally, they had to evaluate the statements about simulators' utilization effectiveness (see Table 3).

Summarized experts' opinion results for JCATS and MILES (I-HITS) simulators' according to statements C1 - C6 ranking are separately presented in Table 4. Additionally, the most frequently repeated answer for each statement is indicated as mode and all criteria were ranked.

Besides, the simulators allow soldiers to train in any virtual battle (or civilian) environment, but the preparation for the training itself requires careful planning, anticipation of the necessary tools, error-free database creation, and all of this, the creation of the special scenario to achieve the training purposes. Continuously all of this preparation is not done properly due to lack of time to prepare for the military training.

Military units which are using simulators are often uninformed of their full potential and the benefits of using simulators. As a result, the efficiency of using simulators is often low.

Sufficient time is spent collecting data from battalions while preparing JCATS and MILES (I-HITS) simulator scenarios. Therefore, there is not always time left to test scenarios and anticipate technical glitches. If these problems did not persist, scenario building and execution would become significantly more efficient.

A lot of time is wasted for staff training to work with the simulators. If this problem did not persist, the preparation would become much more effective. Training of LAF JCATS operators takes a week before the military training. Operators preparation is provided by JCATS specialists. The training lasts five days. Also, training of MILES system users takes place in units, training is performed by MILES specialists, and takes up to one day.

Lithuanian military units could do much more trainings for soldiers with simulators if the simulators will be mobile. The mobile simulators can save time, because it will be spending less time for the exercise's preparation. For example, to take a MILES (I-HITS) control unit to another landfill, its preparation at another location takes up to seven days. Now this situation is improper because the simulator preparation time is too long.

\subsection{Experts' Opinion Similarity Study}

In order to find out whether the answers of the respondents can be used as conducted study result, it is necessary to assess the consistency of the experts' opinions. After reviewing the results of the respondents', it is important to assess the consistency of the opinions of the experts involved in the study by calculating the Kendall concordance coefficients W [11]. If expert opinions are contradictory and coefficient W is forthcoming to 0 , if expert assessments are similar coefficient $\mathrm{W}$ is forthcoming to 1 .

Kendall concordance coefficient W calculation can be performed by formulas presented below:

$$
a=0.5 m(k+1)
$$

when, $m$ is the number of experts, $\mathrm{k}$ is the number of alternatives provided. In the specific case of the conducted study $a=0,5 * 6 *(6+1)=21$.

The sum of the squares of the mean deviations from the sum of the ranks can be calculated by equation: 


$$
S^{2}=\sum_{j=1}^{k}\left(\sum_{i=1}^{m} x_{i j}-a\right)^{2},
$$

when, a is the average of the sum of ranks, and xij is the evaluation of the $j$ alternative of the $i$ expert, when $i=1,2, \ldots$, $m$ and $j=1,2, \ldots, k$. In the specific case of the JCATS simulator utilization study (see Table 4 ) according equation (2) was calculated, the $\mathrm{S} 2=523$. The concordance coefficient can be calculated by the equation:

$$
W=\frac{12 S^{2}}{m^{2}\left(k^{3}-k\right)},
$$

when, $m$ is the number of experts, $k$ is the number of alternatives provided. In the specific case of the JCATS simulator utilization study the concordance coefficient according equation (4) was calculated, the $W=0.830$. The following hypotheses are formulated and tested:

$\mathrm{H}_{0}$ : expert assessments are contradictory $(\mathrm{W}=0)$;

$\mathrm{H}_{\mathrm{a}}$ : expert assessments are similar $(\mathrm{W}>0)$.

Subsequent, to make a decision and chose the one of hypotheses there have to be calculated such a statistic's measure: $=24,9$. These statistics are distributed according to the distribution of , consequently the critical value is calculated. If the actual statistic is greater than the critical value, the null hypothesis of inconsistency is rejected. In this case, the statistic for JCATS simulator utilization (see Table 4) was calculated, and the result $=24.9>$ let make a decision, the null hypothesis had to be rejected and had to be accept the alternative. The obtained concordance coefficient showed that the consistency of expert opinions is sufficient [11].

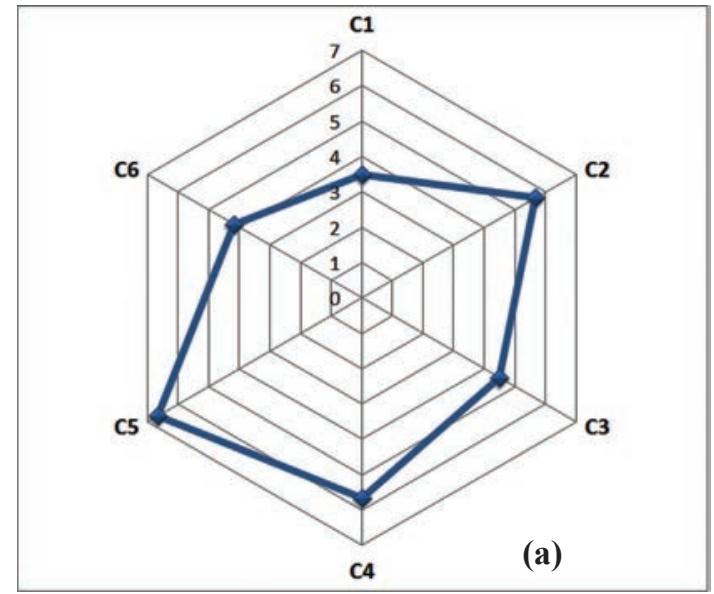

Fig. 3. Experts' opinion on low JCATS simulators utilization glitches. JCATS codes' meanings are presented in Table 3. Source: authors'

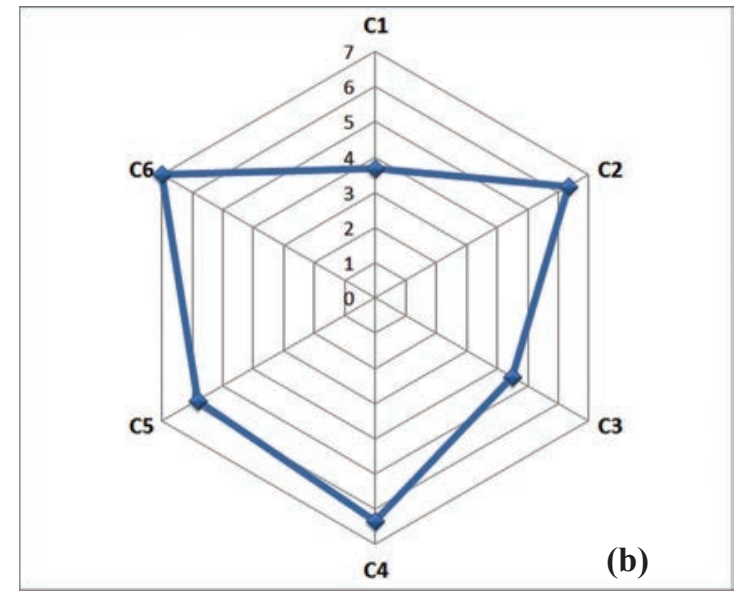

Fig. 4. Experts' opinion on low MILES (I-HITS) simulators utilization glitches. MILES codes' meanings are presented in Table 3. Source: authors'

Concordance coefficient obtained according the MILES (I-HITS) simulators utilization estimating was similarly calculated using an analogous calculation algorithm and (2-4) equations. The calculated coefficients reflect the unanimity of LAF experts' opinions. The calculated concordance coefficients $\mathrm{W} \in[0.83 ; 0.98]$ show that the consistency of expert assessments is sufficient and statistically significant.

Based on the responses of the LAF training unit respondents', the radar diagrams were shaped. The systematized simulator's utilization efficiency evaluation is plotted according C1- C6 statements (with description can be familiarize in Table 3) on a seven-point scale ranging from (1) weak to (7) excellent, taking into account the responses part and the rank given according to statement (see Table 4).

The main causes of improper JCATS simulators utilization in to the soldiers' training process, according to the experts' opinion, can be named: the preparation time, the planning, the simulator compilation difficulties. The preparation of exercises with JCATS simulator takes too long time (C1, Fig. 3) and this cause slowed down all exercise planning (C3, Fig. 3). In addition, JCATS has complications with representation realistic exercises, scripting and compilation glitches (C6, Fig. 3).

The main cause of inappropriate MILES simulators utilization into the training process, according the experts' opinion, is that the military units perform too little training using MILES (I-HITS) simulators (C1, Fig. 4). The experts 
survey identified this luck because for soldiers training is used the too old hardware. The main scheduling problem for MILES (I-HITS) simulators is due to the immobility of the system control unit (C3, Fig. 4), which affects the number of exercises performed using simulators of LAF training unit.

\section{Research Limitations}

There have to be mentioned the main limitations of the evaluation methods which were used to achieve the result. The expert study method lies in its one-sidedness. For instance, the simulator utilization method does not take into account contextual factors, such as didactical, motivational, and organizational aspects of training aids. In case to show the full situation, analysis there have to be analyzed the quality and completeness of the training program, instruction and feedback, or aspects of game play.

In contrast, the quantity method yields an outcome that may be unrelated to real training value because the quality of the simulator itself is not sufficiently taken into account. So, the various aspects of functional and physical simulators' capabilities have to be involved into study as extended data analysis.

Moreover, the analysis of the combined training environment and the didactical and organizational quality assessment as the context in which the simulators are utilized can help to determine training effectiveness as well. Consequently, limitation of this research centers on the representativeness of the data collected in the interviews, focus groups, and investigation. Interviews and focus groups with larger samples of LAF staff and unit warriors who are the consumers of training and from more locations would enhance the external validity or generalizability of the findings. In the case of the study, higher response rates from respondents and getting traction from personnel at LAF training unit, along with recruiting prospective participants with a broader range of military experience, would strengthen the findings.

In future studies, it will be our advice to expand simulators utilization for military demand study and take into account these mentioned limitations.

\section{Conclusions}

The obtained research results showed that complex problems and shortcomings are encountered in the training process using simulators. The combat training needs and expectations of the soldiers serving in the Lithuanian Armed Forces are unsatisfactory. The simulators used or acquired by the Lithuanian Armed Forces meet the requirements of NATO, but based on the opinions expressed by experts, it became clear that the training of soldiers using simulators is not effective, as preparation for JCATS simulator takes too long and influences the number of exercises performed using simulators of LAF combat training centre. Based on the results of the study, the relevant suggestions for a more effective use of simulators in the military training were formulated to help solve the identified problems. To change the situation and solve complex problems and shortcomings which are encountered in the training process using simulators, the solutions are proposed:

- to increase the number of JCATS simulators in the Lithuanian Armed Forces,

- to purchase new MILES equipment and to perform the reconstruction of the (I-HITS) control unit in order to improve the use of existing simulators related to military training.

The above observations allow us to provided rational solutions how to eliminate identified problems of military training. The relevant suggestions were formulated to help to solve the identified problems.

After the implementation of the solutions of the proposed suggestions, it will be possible to achieve wellorganized use of simulators in the soldiers' training process, because:

- Additional JCATS simulators will result in more battalion and brigade-sized military trainings in combat units;

- New MILES equipment will let to perform a larger number of planned and implemented exercises;

- There will be more military trainings using MILES (I-HITS) simulators due to the mobile (I-HITS) control unit, which will save time for exercise preparation. 


\section{References}

1. David E. Johnson, Jennifer D. P. Moroney, Roger Cliff M. Wade Markel, L. S. (2009). Preparation and training for the full spectrum of military challenges.

2. Johnson, David E., et al. Preparing and Training for the Full Spectrum of Military Challenges: Insights from the Experiences of China, France, the United Kingdom, India, and Israel. Santa Monica, CA: RAND Corporation, 2009. Available from: https://www.rand.org/pubs/monographs/MG836.html.

3. Jarmasz, J., Wojtarowicz, D., Dielschneider, J., \& Ueno, K. (2013). Simulation-Based Training for IED Awareness.

4. Korteling, J.E., Oprins, E.A.P.B. \& Kallen, V.L. (2013). Measurement of Effectiveness for Training Simulations, (Report RTO-SAS-095). Soesterberg, The Netherlands: TNO Human Factors Research Institute.

5. Allied command transformation. 2014. Task Group for Individual Training \& Education Developments (IT \& ED). Available from: http://www.act.nato.int/images/stories/structure/jft/NTG-ADL_Guidelines.pdf.

6. Cubic global defence. (2019). MILES (I-HITS). Available from: https://www.cubic.com/sites/default/ files/2019-01/Cubic\%20Corp_2018\%20Annual\%20Report.pdf

7. Market reach future. (2019). Military Simulation and Virtual Training Market. Available from: https://www. marketresearchfuture.com/reports/military-simulation-virtual-training-market-3510

8. Michelle, J. (2014). Professional Military Education: Analysis and Recommendations. Available from: http:// search.ebscohost.com/login.aspx?direct=true\&db=e000tww\&AN=675621\&lang=es\&site=ehost-live

9. Caro, P.W. (1977). Some factors influencing air force simulator training effectiveness HUMRRO Technical Report tr-77-2. Alexandria, Virginia: Human Resources Research Organisation.

10. Kendall, M. G., Gibbons, J. D. (1990). Rank Correlation Methods. - Edward Arnold, London.

11. Čekanavičius V., Murauskas G. Statistika ir jos taikymai. 2 d. 2004, Vilnius:TEV. -270 p.

12. Pincevičius, A.; et al. 2008. Modeling of Infantry Attacks on Real Terrain. Nonlinear Analysis: Modelling and Control, vol. 13(4): 491-501. ISSN 1392-5113

13. Bausys, R.; et al. 2009. The Intelligent Technologies Application for Artillery Control. Intelligent technologies in logistics and mechatronics systems ITELMS ‘2009, Kaunas: Technology, 164-168, ISBN 978-955-25-531-4.

14. Kleiza, V.; et al. 2009. Military Specialist Preparation Features in Nowadays Environment. Intelligent technologies in logistics and mechatronics systems ITELMS‘2009, Kaunas: Technology, 158-163, ISBN 978-955-25-531-4.

15. Bekesiene, S.; et al. The Effective Use of the Intelligent Technologies in Planning Infantry Attacks Intelligent technologies in logistics and mechatronics systems ITELMS‘2009, Kaunas: Technology, 169-173, ISBN 978955-25-531-4.

16. Hošková-Mayerová, Š.; Talhofer, V.; Hofmann, A.; et al. 2013. Mathematical Model Used in Decision-Making Process with Respect to the Reliability of Geodatabase, Advanced Dynamic Modeling of Economic and Social Systems, Book Series: Studies in Computational Intelligence, vol. 448, 143 p.

17. Sitzmann, T. 2011. A meta-analytic examination of the instructional effectiveness of computer-based simulation games. Personnel Psychology, 64, 489-528.

18. Salas, E., Milham, L.M., \& Bowers, C.A. 2003. Training evaluation in the military: misconceptions, opportunities, and challenges. Military Psychology, 15, 3-16.

19. Waniek, P. 2014. Application of the jcats system in computer-aided tactical level command post exercise. 